\title{
ACERCA DEL MOVIMIENTO DE RECONCEPTUALIZACIÓN
}

Norberto Alayón F.1 $M^{\text {a }}$ Lorena Molina M. ${ }^{2}$

\section{RESUMEN}

\begin{abstract}
Analiza el Movimiento de Reconceptualización, desarrollando brevemente una suerte de balance de las influencias recibidas, de sus aportes y limitaciones, rescatando la importancia de este proceso para perfilar un nuevo tipo de Trabajo Social, ligado a los intereses estratégicos de los sectores más vulnerados de la población en consonancia con un enfoque de defensa, promoción, protección y exigibilidad de los derechos humanos. Concluye con una reflexión acerca de los desafíos para la formación profesional.
\end{abstract}

Palabras clave: Reconceptualización - Trabajo Social

\begin{abstract}
This article presents the análisis about the main influences that the "movimiento de Reconceptualización" in Latin América had received. Moreover, it to sets up the contributions and the restrictions of this process; for this it rescues the critic compression coreo $\mathrm{f}$ a new type of social work. All of this was linking with the strategic interests of the vulnerable population. In adition, it argues about the important interrelationship between Social Work and the human rights and the present challenges for the academia formation in this yield.
\end{abstract}

Key words: Reconceptualización - Social Work

os procesos de cambio progresivo o de retroceso en las disciplinas no son un producto meramente endógeno de cada profesión. Se generan y se articulan con la dinámica social y política específica que se registra en un momento histórico determinado.

De ahí que el Trabajo Social, como cualquier otra disciplina, no constituye una categoría abstracta que funciona independientemente de las determinaciones histórico-sociales, que se registran en tal o cual país en un período particular. En virtud de ello -ayer y hoy- resulta

${ }^{1}$ Profesor Titular Carrera de Trabajo Social, Universidad de Buenos Aires. Argentina. Ex-ViceDecano Facultad de Ciencias Sociales. Universidad de Buenos Aires. Ex-Coordinador Académico del CELATS.

${ }^{2}$ Profesora Catedrática Escuela de Trabajo Social, Universidad de Costa Rica. Vice - Decana Facultad de Ciencias Sociales. Universidad de Costa Rica. Ex-Presidenta de ALAETS- CELATS. 
imprescindible analizar al Trabajo Social en el contexto de los procesos sociales, económicos y políticos vigentes.

Hechas estas rápidas puntualizaciones, veamos, entonces, de precisar algunas cuestiones -no todas- inherentes al llamado Proceso o Movimiento de Reconceptualización en nuestra profesión. No vamos a abordar, en esta ocasión, el análisis detallado de los hechos políticos, económicos y sociales que se registraron en América Latina en el período de gestación y consolidación de este importante Movimiento, que podemos ubicar principalmente entre mediados de la década de los 60 y mediados de la década de los 70.

Sí creemos oportuno destacar las grandes influencias teóricas y políticas que recibió el movimiento. Los principales aportes provinieron de la teoría de la dominación y la dependencia, del marxismo, de las propuestas "concientizadoras" del pedagogo brasileño Paulo Freire y también de la teología de la liberación.

Nuestra profesión, en efecto, recibió en ese período un shock conceptual y político de enorme oxigenación, pero -a la vez- de no tan fácil absorción de sus diversos y complejos componentes.

Esas contribuciones alteraron notable y favorablemente el campo profesional y generaron, por cierto, un salto cualitativo en los inicios de la teorización al interior del Trabajo Social. Convengamos, no obstante, para ser respetuosos de la historia, que en muchos casos se verificaba una comprensión simplista y de mucho reduccionismo acerca de las variadas nociones y teorías que "desembarcaban” en el ámbito de la profesión.

Las adscripciones ideológicas y políticas de los y las colegas que adherían a la emergencia de la Reconceptualización eran bien disímiles: católicos, ateos, evangelistas; peronistas, frondizistas, comunistas, socialistas, demócrata cristianos. Coincidíamos sí en un fuerte y creciente sentimiento antinorteamericano, que nos generaba rechazo casi frontal a todo lo que proviniera de Estados Unidos.

Nos sonaba tan cercano el presagio del Libertador Simón Bolívar -que sigue vigente hoyquien en 1829 había escrito en Guayaquil que "los Estados Unidos... parecen destinados por la Providencia para plagar a la América de miserias a nombre de la libertad...".

De todos modos, resulta necesario precisar -aunque sea obvio- que es incorrecto asociar las aportaciones de los intelectuales norteamericanos, como si, en todos los casos, existiera un correlato irreductible con las orientaciones que impulsa el modelo imperial de sojuzgamiento de otros países, asumido permanentemente por los Estados Unidos.

Desde el propio vientre del "animal imperial", desde el centro mismo del orden social capitalista más brutalmente exitoso, surgen también voces y aportes profundamente contestatarios y progresistas, con los cuales debemos ensamblarnos para sumar fuerzas en la perspectiva de contribuir a la construcción de sociedades más equitativas y justas.

El revuelo y convulsión que habían ocasionado las nuevas ideas en los profesionales más tradicionales, dio paso luego a las denuncias y estigmatizaciones hacia los sectores más activos que adherían a las nuevas corrientes de la Reconceptualización. Hacia el año 1969 fueron paradigmáticas las acusaciones de la asistente social argentina Marta Ezcurra, Vicepresidenta para 
América Latina de la Unión Católica Internacional de Servicio Social (UCISS). Ezcurra, representante del pensamiento lúcido del catolicismo conservador, acusó al Grupo ECRO de Argentina y a colegas de Uruguay y de Chile de ser "cabeceras organizadas del movimiento comunista dentro del Servicio Social".

Marta Ezcurra, en su país, había sido Directora Nacional de Asistencia Social durante la dictadura militar de la llamada "Revolución Libertadora”, que derrocó a Juan Domingo Perón. Desempeñó su cargo entre 1955 y el 15 de mayo de 1958, debiéndose recordar que el $1^{\circ}$ de mayo de ese año asumió el Dr. Arturo Frondizi como Presidente constitucional, el cual era considerado por diversos sectores como "filo comunista".

En julio de 1967, bajo otra dictadura militar encabezada por el Gral. Juan Carlos Onganía, excelso representante del nacionalismo católico y oligárquico, se realizó en Buenos Aires -con más de 1.200 participantes de Argentina y de otros 25 países del mundo- el XI Congreso Mundial de la UCISS, con el tema "Promoción Humana y Servicio Social. Responsabilidad de los Cristianos". Precisamente Marta Ezcurra fue una de los Presidentes del Congreso, con discursos inaugurales del Dr. Raúl Puigbó y de clausura del Dr. Adolfo Critto, Secretario y Subsecretario, respectivamente, de Promoción y Asistencia de la Comunidad del gobierno militar, cuyos máximos dirigentes se auto presumían de cristianos.

También, desde otras perspectivas, se abominó de la Reconceptualización. La trabajadora social argentina Alicia Peire expresó recientemente que: "La reconceptualización era para aquellos que no estaban en las organizaciones armadas y que tenían tiempo para hacer la reconceptualización. Nosotros discutíamos si estaba bien que lo hubieran matado a Rucci o no. Yo me enteré de la reconceptualización por alguna revista que llegó a mis manos que no sabía de qué era, era de otro ámbito, de la gente que estaba en la academia. Nosotros éramos militantes que aparte teníamos un título, que no era ningún orgullo...”.

El desprecio hacia la actividad intelectual y académica y la idealización cuasi religiosa de las acciones armadas, también colisionaron con este proceso de transformación de la profesión. Algunos atacaban a la Reconceptualización por "comunista" y otros la atacaban por "academicista".

En rigor, el movimiento de Reconceptualización se había iniciado con un sesgo de adhesión al modelo desarrollista, para luego ir transitando hacia posiciones más radicalizadas, en la perspectiva de posicionar el quehacer del Trabajo Social en el marco de la opresión y explotación que sufría América Latina y de las emergentes y/o inminentes experiencias “revolucionarias". El impacto de la experiencia socialista cubana iniciada en 1959, los aires del Mayo Francés de 1968 y la asunción del socialista chileno Salvador Allende en 1970, eran propiciatorios, a pesar de que Argentina estaba en dictadura desde 1966 a 1973 y luego de 1976 a 1983; Uruguay lo mismo desde 1973 a 1984; Brasil también desde 1964 a 1985; y Chile luego desde 1973 a 1990. En Centroamérica las dictaduras fueron también el rasgo característico, excepto para Costa Rica, país que para los años sesenta y setenta caminaba hacia una significativa ampliación de la política social en el marco de un régimen político de democracia representativa, y cuya única universidad estatal en 1972, aprobaba reformas a su estatuto orgánico con explícitas definiciones en los propósitos, 
a favor de las transformaciones sociales necesarias para mejorar las condiciones de vida de las mayorías y además, señaló desde entonces, la integración de la investigación, la docencia y la acción social en el proceso educativo.

El sociólogo chileno Diego Palma hacía referencia a tres líneas de hipótesis básicas, en relación a este movimiento de la profesión:

- La Reconceptualización brota cuando el desencanto con la función del Servicio Social tradicional se cruza con la elevación continental de la expectativa de transformación social.

- El movimiento se desarrolla primariamente en los países que logran una cierta agudización de la lucha de clases.

- Los grupos reconceptualizadores se concentran sobre las Universidades o se ligan a las iglesias.

Por su parte, la trabajadora social y antropóloga argentina Estela Grassi certeramente analizaba en 1994, que:

"Con el Movimiento de Reconceptualización los trabajadores sociales de esta corriente asumieron para si -de la manera más activa a lo largo de su bistoria-la tarea de conceptualizar tanto el objeto de su intervención como su práctica. El marco general de la reconceptualización estuvo dado por: a) una fuerte politización de la sociedad en general; b) el desarrollo de corrientes críticas en las ciencias sociales, fundamentalmente de inspiración marxista o de lo que se denominó en nuestro país el "pensamiento nacional" (en el que se hicieron confluir categorías marxistas con el ideario peronista); y c) el establecimiento de una relación más estrecha de estas corrientes con la práctica política. Paradójicamente, estas circunstancias -de hecho, movilizadoras de los cambios en el interior de la profesión-al combinarse con aquella tradición de activismo, no dieron lugar a la consolidación de una corriente crítica teóricamente sólida dentro de la profesión".

Las y los trabajadores sociales comenzamos a identificar y reconocer el origen de la desigualdad social en las relaciones de dominación vigentes en la sociedad, cuestionando las propuestas de integración al medio de los "desadaptados" o "marginados", propias de aquel pensamiento "modernizador" y de las concepciones teóricas funcionalistas, propuestas éstas provenientes de la óptica de entender como justo y adecuado el modelo imperante.

Y se impugnaron las tendencias más tradicionales, previas aún al propio desarrollismo, que asumían la desigualdad social como una suerte de hecho natural. El principio de causación individual era atribuido a quienes padecían los problemas sociales, desconectando la relación existente entre el funcionamiento global de la sociedad y la presencia de los llamados "males sociales". De ello derivó el cuestionamiento a la mistificación de la posibilidad de superación global de los problemas sociales, mediante el esfuerzo individual de los propios damnificados.

Por sobre estos evidentes avances conceptuales, es cierto también que las y los trabajadores sociales quedamos entrampados con varios espejismos. Del mismo modo que en la época del desarrollismo, nos habíamos cautivado y caímos en la ilusión de que el trabajador social podía constituirse en el "agente de cambio" para el seguro y rápido advenimiento del desarrollo; luego 
-en la época de la Reconceptualización- volvimos a ilusionarnos con la creencia de que el Trabajo Social podía ser el eje de la transformación social.

La aspiración del cambio estructural de la sociedad, en pos de su mejoramiento, es absolutamente legítima, pero trasciende las funciones específicas de las profesiones.

Tomar conciencia del papel que venía cumpliendo la profesión en el mantenimiento y reproducción de un orden social injusto, condujo irremediable y felizmente (en especial a las nuevas camadas de graduados y estudiantes) a un acelerado proceso de politización del campo profesional.

Ese objetivo avance produjo, no obstante, cierto sentimiento de desvalorización de la profesión, empujando a algunos sectores de colegas al rechazo y hasta abandono del Trabajo Social, optando por diversas formas de acción política directa.

Un aspecto clave que no pudo ser debidamente procesado -y que aún en la actualidad está insuficientemente trabajado- es el referido al papel de las y los trabajadores sociales al interior de las instituciones, especialmente del Estado, donde nos desempeñamos mayoritariamente. Las polarizadas y agrias discusiones que abroquelaron a los profesionales de la época, entre aquellos a quienes se les adjudicaba la realización de prácticas rutinarias y tradicionales y aquellos otros que aspiraban a la implementación de prácticas alternativas y "revolucionarias" y que en muchos casos decidían el abandono de las instituciones, no resultaron conducentes -en la mayoría de las vecespara el mejoramiento del Trabajo Social.

Las instituciones eran y son ámbitos de lucha; espacios complejos donde se dirimen posiciones contradictorias; lugares de disputa de poder en pro del cambio o del mantenimiento de lo existente. En definitiva, "si se quiere atrapar al cachorro, no hay más remedio que meterse en la guarida del león".

Sin un proceso de cuestionamiento maduro y de construcción de propuestas alternativas, los cambios institucionales no llegarán a concretarse. Para ello, será necesario desplegar una práctica profesional, inteligente y fundamentada, llevada a cabo en el propio ámbito específico donde se procesan y atienden las problemáticas sociales.

Un autor peruano, de innegable filiación marxista, Alejandrino Maguiña Larco, nos decía en 1981: "Desviaciones izquierdistas, sin embargo, buscarían desde la Reconceptualización otorgarle a la profesión un carácter de clase que no le correspondía, desarrollando posiciones opuestas al trabajo institucional, así como rechazando la asimilación de las llamadas "ciencias burguesas". Esto es, a nombre de una mala asimilación del marxismo, durante la década del setenta la profesión perdió puntos en lo que respecta a la formación académica más integral del estudiantado. Hace ya un lustro, por lo menos, (afirmaba Maguiña) que tales desviaciones vienen siendo criticadas, y en la actualidad bien se puede decir que crece un nuevo movimiento de búsqueda -aún no bautizado- que pugna por defender el nivel de politización alcanzado, a la vez que se esfuerza por abrir el panorama cultural más amplio, otorgando a los nuevos profesionales las mayores facilidades para su perfeccionamiento técnico". 
Y Diego Palma también decía, en 1977: "Se cae en el materialismo histórico y dialéctico por motivos ideológicos más que científicos. Resulta entonces que detrás de una verborragia que utiliza todos los términos del discurso del materialismo, se puede esconder una práctica sumamente tradicional. Esto sucede porque el pensamiento de referencia se ha desarrollado básicamente en el análisis del cambio macro social, pero no ayudan (sin un esfuerzo de aplicación) para la categorización del universo de prácticas particulares del Trabajo Social".

Queremos aclarar que, en modo alguno con estos recordatorios, nos proponemos realizar una prédica antimarxista. Valoramos profundamente las contribuciones provenientes del marxismo para desentrañar y develar el funcionamiento de las sociedades, como así también para proponer cursos de acción que posibiliten remover las trabas que impiden el necesario cambio. Pero ello no nos debe inhibir para señalar las desviaciones en que incurren ciertos actores, que terminan desvirtuando y esterilizando los vigorosos aportes del marxismo a la teoría social y política.

Sin embargo y a pesar de estas limitaciones, el proceso de Reconceptualización -como expresa el colega brasileño José Paulo Netto - "constituyó y constituye el paso más relevante de la historia del Trabajo Social”. Y coincidimos con otro trabajador social brasileño -Vicente de Paula Faleiroscuando afirma que "la línea de análisis crítico y de oposición a las tendencias tradicionales o modernizantes (que constituyó la esencia de la Reconceptualización) está debilitada pero no muerta".

Nosotros reafirmamos que la perspectiva de "análisis crítico" requiere ser fortalecida y puesta en práctica en forma permanente. Recuperar el espíritu crítico, que caracterizó a la Reconceptualización, constituirá un importante aporte para identificar las distintas orientaciones que, con aciertos y desaciertos, la profesión fue y va adoptando -a veces espasmódicamente- en el transcurso histórico.

Conviene recordar que desde sus inicios con una concepción meramente asistencial, la profesión fue transitando y asumiendo diversas variantes y opciones: el desarrollo de la comunidad, el considerar al y a la trabajadora social como "agente de cambio", la pretensión de una concepción "revolucionaria", la inmersión en las corrientes psicologistas, la incorporación del llamado Servicio Social Polivalente, la adopción del enfoque sistémico, las propuestas de mediación, el camino hacia la gerencia social, etc.

Hace ya casi 30 años, Alayón escribió que: "El Trabajo Social es lo que es, y entendemos que -si se posee una correcta ubicación- se pueden realizar aportes interesantes que favorezcan a la organización y movilización de los sectores populares en pos de sus intereses. No obstante ello, entendemos que el trabajador social que se proponga eliminar la explotación, transformar la actual sociedad capitalista dependiente, es decir, luchar por la revolución nacional y social que el país y América reclaman, debe elegir otro camino que no es precisamente el Trabajo Social ni ninguna otra profesión. Lo expresado anteriormente -decíamos en esa ocasión- no aspira a inhabilitar el Trabajo Social; aspira a definirlo seriamente". 
Y hoy, que estamos más expoliados aún, más dependientes, más empobrecidos, más debilitados, tendremos que volver a pensar cautelosa pero firmemente en la posibilidad de recreación de un Trabajo Social que permita contribuir, a partir de prácticas institucionales y comunitarias específicas, a la más amplia defensa de los derechos sociales vulnerados y a la preservación y aumento de la calidad de vida de los sectores más castigados, colaborando con la urgente tarea de sustraer a nuestros países de este hundimiento generalizado.

Sin duda alguna la Reconceptualización marca un hito fundamental en la forma de entender hoy la historia y razón de ser de esta profesión. El cuestionamiento:

- a la tradición evolucionista explicativa del origen de la profesión,

- al soporte empirista naturalizador de los problemas sociales, y

- a la intervención atomizada o pulverizada desde la acción estatal, es, a nuestro juicio, una de las principales contribuciones para fraguar la génesis de un pensamiento crítico del Trabajo Social.

Todo esto es posible que se desarrolle a partir de la semilla de la autocrítica, nacida allí, en este movimiento. Como vimos, este movimiento tuvo un desarrollo diverso en su primera década y nos llevó a planteamientos simplistas y negadores de la historia misma, los cuales se resumen en el "mesianismo"- ilustrado con el "rol de agente de cambio"- y el "fatalismo", inmovilizador y negador de la capacidad creativa derivado de la comprensión instrumentalista, mecánica del papel del Estado y de la inserción que en él hace el trabajo profesional. Sin embargo, lo cierto es que, es la cuna del pensamiento crítico del Trabajo Social.

Las desviaciones en el estudio de un "marxismo sin Marx", como lo señaló Consuelo Quiroga -en un Taller sobre Teoría y Metodología del Trabajo Social en la Universidad de Costa Rica en 1990 y como lo argumenta en su texto publicado en la revista Acción Crítica-, nos condujeron a la bizantina discusión referida a que el materialismo histórico nos explica el macro entorno y las causas estructurales de las problemáticas desde donde se inician las intervenciones profesionales, pero resulta insuficiente para la intervención en el mundo microsocial y cotidiano. De allí en adelante, vinieron las marchas, las contramarchas con la restauración de los métodos clásicos y la vuelta a la psicologización de las manifestaciones de la desigualdad social. Creemos que al estudiar un "marxismo sin Marx", nos quedamos atrapadas y atrapados.

Hoy pensamos que si pudiésemos retomar el estudio de la dialéctica de la naturaleza humana, la ontología del ser social desde la tradición marxista, la teoría del valor del trabajo , así como desarrollar investigación sostenida sobre las manifestaciones de la cuestión social ,desde donde se configuran los objetos particulares de la intervención profesional como le denominan Molina y Romero (2001) y sobre cómo hemos realizado estas intervenciones sociales ${ }^{3}$ podríamos avanzar, no sólo en el sentido de construir aportes a la teoría social y hacer disciplina, trascendiendo los muros que nos aprisionan cuando sólo nos miramos a nosotros mismos, sino sobre todo,

\footnotetext{
${ }^{3}$ No nos referimos a estudiar las intervenciones en la cuestión social sólo desde esta profesión, puesto que desde la noción de totalidad concreta, siguiendo a Kosick (1976) cabemos más en la comprensión de las formas de producción y reproducción social.
} 
desde la responsabilidad ético político que implica soñar un mundo con equidad. Esto sin duda será fortalecer el sentido crítico del proceso de la reconceptualización, pero,sin mecanicismos y esquemas simplificadores de la realidad.

O sea, si asumimos que en la historia está la fuente de nuestros problemas y también en ella la búsqueda de las soluciones y entendemos que, como profesionales nos posicionamos en una ética expresada en la defensa, promoción, protección y exigibilidad de los derechos humanos (aunque la ley no necesariamente sea expresión de equidad en su realización), los parámetros de la intervención se reconfiguran. No es lo mismo, diagnosticar desde un enfoque de necesidades/ carencias de satisfactores (porque cabe interrogarse: ¿cuáles son los parámetros de referencia? ¿la conciencia de las carencias del sujeto o los parámetros del profesional para decidirle al otro lo que necesita?) o posicionarse en el enfoque de derechos humanos para diagnosticar lo que se violenta, lo que no se accesa y ante lo cual corresponde generar mecanismos de exigibilidad (individuales, familiares, grupales, organizacionales, barriales, etc). Todo esto implica forjar conciencia de ciudadanía ampliada consecuente con la radicalización de la democracia en el significado que le atribuye Agnes Heller.

De lo anterior deviene la pertinencia y urgencia de desarrollar una politización de la acción profesional- desde cada sujeto profesional y desde la acción corporativa gremial- para la defensa y exigibilidad de los derechos humanos, en tanto es la promesa no cumplida de la modernidad y además es un discurso legítimamente aceptado, aparentemente no transgresor del orden.

Ahora bien, lo trascendente es posicionarse en la mirada de la radicalización de la democracia, entonces el texto de los derechos humanos se configura en un discurso estratégico para la acción con los desfavorecidos del sistema, a partir de las exigencias de la cotidianidad de los sujetos sociales, en tanto son producto histórico. Por ello, esa cotidianidad debe ser comprendida como expresión de determinantes económicos, sociales y culturales construidos en cada nación y en su reproducción individual, familiar, local. Esto pasa necesariamente también por convertirnos en sujetos de transformación de las organizaciones corporativo gremiales.

En el plano de la formación académica asumir el legado de la Reconceptualización es un desafío crucial. Es fundamental formar futuros profesionales de pensamiento, acción crítica, propositiva y con compromiso ético político surgido del estudio de la cotidianidad como expresión histórica y con capacidad estratégica para:

- investigar las manifestaciones y la configuración de la cuestión social con las transformaciones en el mundo del trabajo (producción) y de las familias (reproducción social) en el marco de las relaciones sociales marcadas por la sociedad patriarcal y la lógica capitalista como punto medular para construir la intervención profesional desde el Trabajo Social.

- comprender a los seres humanos en su universalidad y particularidad, así como la diversidad que hay en ellos y las formas de discriminación que viven por criterios: socioclasistas, de género, étnicos, de edad, opción sexual, religión, etc. Esto implica, plantearse los derechos humanos como eje curricular en cuanto doctrina e instrumentos de protección, pero sobre todo, su problematización ya que su no realización expresa la desigualdad social y por ello 
-desde nuestro entender- esto constituye un escenario en lo pedagógico y en lo profesional, comprendido como un terreno de formación profesional, de denuncia y de ejercicio de la ciudadanía. ${ }^{4}$

- involucrarse y comprender las respuestas desde las organizaciones y movimientos sociales en la lucha por la vida.

- asumir con criticidad las respuestas fragmentadas desde la política social en la lógica neoliberal en el manejo de la cotidianidad de las familias incluidas y excluidas en los procesos de trabajo con y sin protección social estatal.

- posicionarse en los espacios de defensa de los derechos como profesional orgánico a favor de los intereses de la mayoría, pero entendiendo el juego de poder institucional para argumentar cambios en la formulación, gestión y ejecución de las políticas sociales.

- ser parte de la formulación de proyectos de ley o bien articularse a las organizaciones de la sociedad civil para incidir en la política o en los cambios a la ley.

Todo lo anterior pasa también por: una docencia asentada en líneas de investigación que refieran al meollo del asunto o sea las manifestaciones históricas de la desigualdad social expresadas en la cotidianidad de los sujetos y las diversas formas de intervenir en lo social como base de la enseñanza y fuente de denuncia social. Sin investigación no comprenderemos la historia y la manifestación cotidiana en la diversidad de los seres humanos en su expresión universal, particular y singular y corremos el riesgo de no ser pertinentes, es decir de perder legitimidad social como profesión.

\footnotetext{
${ }^{4}$ En 1992 Molina participó en la discusión y preparación de un texto para las Escuelas de Trabajo Social y los y las profesionales en Trabajo Social sobre la doctrina y los instrumentos internacionales de protección, convocado por el Centro de Derechos Humanos de Naciones Unidas en Ginebra, Suiza. Dicho taller contó con el auspicio de la FITS y la IASSW. Esta experiencia y la participación en el Curso Interdisciplinario de Derechos Humanos (1987) -organizado por el Instituto Interamericano de Derechos Humanos, con sede en Costa Rica- sientan las bases para la reflexión sobre el potencial que posee el discurso de los derechos humanos para la formación y el trabajo profesional. De igual manera, para Alayón la práctica por la lucha y la defensa de los derechos humanos, así como, su contribución sobre el señalamiento de la asistencia social como derecho de la población pobre son marcas que definen la comprensión actual del Trabajo Social de ambos autores, lo cual se expresa en este artículo.
} 


\section{REFERENCIAS BIBLIOGRÁFICAS}

ALAyÓn, NORBERTO (1992). Historia del Trabajo Social en Argentina. Buenos Aires. Espacio. 4ta. edición. alayón, norberto (1988). Perspectivas del Trabajo Social. Buenos Aires. Hvmanitas. 2da. edición.

ALAYÓN, NORBERTO (1976). “Trabajo Social: ¿Profesión o Revolución? En: Varios Autores. Desafío al Servicio Social ¿Está en crisis la Reconceptualización? Buenos Aires. Hvmanitas.

Centro de derechos humanos (1995). Derechos Humanos y Trabajo Social. Nueva York y Ginebra. Naciones Unidas.

FALEIROS, VICENTE DE PAUla (1987). “Confrontaciones teóricas de la Reconceptuación”. En: Revista Acción Crítica $\mathrm{N}^{\circ}$ 21. Lima. ALAETS/CELATS.

GRASSI, ESTELA (1994). "La implicancia de la investigación social en la práctica profesional del Trabajo Social". En: Revista de Treball Social $\mathrm{N}^{\circ} 135$. Barcelona, España. Col-legi Oficial de Diplomats en Treball Social de Catalunya.

GRASSI, ESTELA (1989). La mujer y la profesión de Asistente Social. El control de la vida cotidiana. Buenos Aires. Hvmanitas.

KOSICK, KAREL (1976). Dialéctica de lo Concreto. México. Editorial Grijalbo.

maguiña larco, alejandrino (1981). "El Trabajo Social y las Ciencias Sociales". En: Revista Acción Crítica. $\mathrm{N}^{\circ}$ 9. Lima. ALAETS/CELATS.

MOLINA, $\mathrm{M}^{\circ}$ LORENA y ROMERO, $\mathrm{M}^{2}$ CRISTINA (2002). "Las cuestiones sociales y la intervención profesional".

En: Revista Costarricense de Trabajo Social. Na13. Costa Rica.

MOLINA, Ma LORENA y ROMERO, Mª CRISTINA (2001). Modelos de atención asistencial, socioeducativa y terapéutica en Trabajo Social. Costa Rica. Editorial Universidad de Costa Rica.

MOLINA, Ma LORENA y ROMERO, Mª CRISTINA (1996) "Situaciones críticas de la intervención profesional: retos para la formación académica”. En: Revista Costarricense de Trabajo Social. No 11. Costa Rica. MOLINA, Ma LORENA y ROMERO, Ma CRISTINA (1996) "Las concepciones subyacentes en el currículo de

Trabajo Social". En: Cuadernos de Trabajo Social. Nª9. España. Universidad Complutense de Madrid MOLINA, Ma LORENA (1991). "Enseñanza - aprendizaje de los derechos humanos en las Escuelas de Trabajo Social". En: Revista Costarricense de Trabajo Social. N² 2. Costa Rica.

NETTO, JOSÉ PAULO (1981). "La crítica conservadora a la Reconceptualización". En: Revista Acción Crítica $\mathrm{N}^{\circ}$ 9. Lima. ALAETS/CELATS.

palma, Diego (1977). La Reconceptualización. Una búsqueda en América Latina. Buenos Aires. ECRO (Serie CELATS 2).

QUIROGA, CONSUELO (1990). 'Una invasión invisible: reducciones positivistas en el marxismo y sus manifestaciones en la enseñanza de la metodología en el Servicio Social".En Revista Acción Crítica, $\mathrm{N}^{\circ}$ 27. Lima. ALAETS/CELATS.

uciss-Unión Católica Internacional de Servicio Social (1967). XI Congreso Mundial de Servicio Social. Buenos Aires. Hvmanitas.

VARios Autores (2003). La Cullen, una historia de militancia. Buenos Aires. Agrupación de Trabajo Social "Lucía Cullen".

VARIOS AUTORES (1983). Trabajo Social en América Latina. Balance y Perspectivas. Lima. CELATS.

Recibido en junio 15 de 2004

Aprobado en agosto 24 de 2004 